\title{
Mechanical properties of stent-graft materials
}

\section{Authors:}

\author{
Isa C. T. Santos
}

Instituto de Engenharia Mecânica e Gestão Industrial, Faculdade de Engenharia, Universidade do Porto, Portugal

\section{Alexandra Rodrigues}

Instituto Superior de Engenharia de Lisboa (ISEL); ICEMS - Instituto de Ciência e Engenharia de Materiais e Superfícies, Instituto Superior Técnico (IST), Portugal

\section{Lígia Figueiredo}

ICEMS - Instituto de Ciência e Engenharia de Materiais e Superfícies, Instituto Superior Técnico (IST), Portugal

\section{Luís A Rocha}

Instituto de Polímeros e Compósitos, I3N, Universidade do Minho, Portugal

João Manuel R. S. Tavares

Instituto de Engenharia Mecânica e Gestão Industrial, Departamento de Engenharia Mecânica, Faculdade de Engenharia, Universidade do Porto, Portugal

corresponding author

João Manuel R. S. Tavares, Faculdade de Engenharia, Universidade do Porto, Rua Dr. Roberto Frias, s/n 4200-465 Porto, Portugal, Email: tavares@fe.up.pt

\begin{abstract}
An aneurysm is a localized blood-filled dilatation of an artery whose consequences can be deadly. One of its current treatments is endovascular aneurysm repair (EVAR), a minimally invasive procedure in which an endoprosthesis, called a stentgraft, is placed transluminally to prevent wall rupture.
\end{abstract}


Early stent-grafts were custom designed for the patient through the assembling of off-the-shelf components by the operating surgeon. However, nowadays, stentgrafts have become a commercial product. The existing endoprostheses differ in several aspects, such as shape design and materials, but they have in common a metallic scaffold with a polymeric covering membrane.

This paper aims to gather relevant information for those who wish to understand the principles of stent-grafts and even to develop new devices. Hence, a stent-graft classification based on different characteristics is presented, and the significant features of an ideal device are pointed out. Additionally, the materials currently in use to fabricate this type of prosthesis are reviewed and new materials are suggested.

\section{Keywords}

Aneurysm; stent-graft; materials; mechanical properties; review. 


\section{Introduction}

An aneurysm, also known as aneurism, is a bulge in a weakened portion of a blood vessel wall much like the bulge that results from over-inflating a tube. Generally, an aneurysm can be defined as a permanent and irreversible localized dilatation of an artery, having at least a $50 \%$ increase in diameter compared with the normal one [1].

Aneurysms occur most commonly in the aorta, as well as in arteries located at the base of the brain and in the legs. If left untreated, they may burst or rupture causing a hemorrhagic stroke - in the case of brain aneurysms - or, when located in the aorta or other abdominal vessels, hipovolemic shock, and even death, due to massive blood loss.

Aortic aneurysms, both thoracic and abdominal (Fig. 1), although relatively indolent, are severe diseases. It is estimated that thoracic aortic aneurysms (TAA's) affect 10.4 per 100,000 person-years [2] while abdominal aortic aneurysms (AAA's) affect between 12 to 15 per 100,000 person-years [3].

Since the early 1950s, the common treatment of aortic aneurysms has consisted of an open surgery and the replacement of the diseased segment of the aorta by a synthetic graft $[4,5]$. However, as far as AAA's is concerned, population-based studies suggest the mortality rates associated to this procedure are significant with mortality rising to $8 \%$, and $10 \%$ of patients may present cardiac complications, respiratory failure or renal failure $[6,7]$.

In the early 1990s, Volodos (in Ukraine) and Parodi (in Argentina) demonstrated that the transluminal placement of a graft within an AAA was a safe and feasible procedure that can be a suitable alternative to the open surgery [8]. In 1994, Dake confirmed that the procedure was practicable as well in the case of TAA's [9]. Presently, published data shows that the treatment of both abdominal and thoracic 
aortic aneurysms is also viable with total laparoscopy or assisted laparoscopy [10, $11]$.

Endovascular aneurysm repair, or EVAR, is a percutaneous minimally invasive procedure in which an endoprosthesis, i.e., a stent-graft, is guided from the femoral artery to the affected artery segment. The objective of this procedure is to shield the aneurysm sac from the blood pressure and, thus, prevent the rupture of the artery wall.

Stent-grafts are one of the key elements in the EVAR's success. In the first applications, the devices were designed individually for the patient but, presently, several commercial devices, which have different designs and are made of distinct materials, are available. The introduction of such devices increased the availability of EVAR, allowing the selection of the appropriate device for each patient and/or pathology [12]. Although there are several publications describing the devices currently available in the market and the features that stent-grafts should include, there is no document that approaches the properties of the materials used. Thus, this papers intents to fill this gap. The information gathered here allows an enhanced comprehension of stent-grafts as well as establish guidelines for improving them.

This paper is organized as follows. After the introduction, a classification scheme for stent-grafts based on different characteristics is proposed. Next, the "ideal" stentgraft is introduced and described. In the subsequent section, the materials used are itemized, and their most relevant features and performances are indicated. Additionally, the manufacturing processes are addressed. Finally, a reflection on promising materials for stent-grafts is presented.

\section{Classification of stent-grafts}

A stent-graft is an endoprosthesis classified as a class III medical device both in Europe and in the USA. It can be defined as a tubular device composed of a flexible 
membrane, i.e., a graft, supported by a rigid structure. The skeleton, called the stent, acts as an arterial attachment mechanism and provides structural support to both the graft and the treated vascular segment. The graft forms a new conduit that protects the diseased artery from the pulsatile blood pressure.

These medical devices have been used in the treatment of aneurysms, aortic dissection, trauma and occlusive pathologies. According to the illness and the deployment site in which they are applied, their requirements as well as their design differ. Table 1 presents a classification based on different characteristics such as shape, deployment technique, and fixation method.

Regardless of the shape, stent-grafts present distinct combinations of proximal and distal ends as Fig. 2 illustrates. However, the design of the stent-graft has implications for the deployment site and influences the sealing performance and the migration resistance. For example, when selecting a stent-graft for an aneurysm with a short neck or a tortuous anatomy, the selected device should have a small first covered spring because such a design does not compromise the sealing and assures full apposition of the device. If the device is to be deployed near a peripheral artery, a device whose termination does not interrupt the blood flow, e.g., scalloped flares (Fig. 2a) or bare stent (Fig. 2f), is preferable. Currently, in the market, one can find fenestrated and branched stent-grafts [13]; these devices are suitable to treat aneurysms that involve peripheral arteries in order to maintain the blood flow.

In stent-grafts with sinusoidal stents, the number of apexes influences the sealing: the higher the number of apexes, the higher the number of points that press the graft onto the artery providing superior sealing.

\section{“Ideal" stent-graft}

The earliest devices used for EVAR were custom designed for each patient, by the operating surgeon assembling individual parts. Since then, numerous aortic 
endografts have been developed worldwide and are now commercially available $[12,14]$. The design of the devices has remained the same, but some of the early problems, such as stent fracture and graft rupture, have been solved by using new materials and manufacturing techniques. In addition, improvements occurred in the deployment system. Nowadays, it is possible to identify a more or less consensual definition of how an ideal stent-graft should perform; some of those features are presented below.

Biocompatibility, i.e., the ability of a material to remain biologically innocuous during its functional period inside a living creature [15], is of decisive importance since stent-grafts are placed inside the human body in direct contact with blood. Hence, the materials chosen, besides being biostable, cannot be toxic, allergic or carcinogenic; they also cannot cause thrombosis and hemolysis. It is desirable that they promote a thin hyperplasia, but the human body must tolerate them so as not to cause a foreign body reaction or an inflammatory reaction. Furthermore, the device should be capable of being adequately sterilized and stored as an "off-theshelf" product.

The "ideal" stent-graft should have and maintain the same compliance as a normal aorta without interfering with the surrounding anatomical structures. Additionally, its design ought to be the least invasive possible and be able to conform to the aorta's anatomy in order to minimize flow resistance and pressure drops. In fact, the best stent-graft will be the one that can overcome most of the anatomical obstacles, thus achieving success in the largest number of cases.

Stent-grafts should also mimic the aorta's mechanical properties. Not only should they exceed the patient's life expectancy, but they also should be flexible so that the profile can be maintained without kinking or bending. They should be tough yet ductile in order to avoid stent fracture and later complications. Furthermore, to withstand the continuous pulsatile blood flow, they should be fatigue resistant, 
wear resistant and have a stable configuration, i.e., they cannot allow excessive elongation, overexpansion or bursting.

The rate of tissue ingrowth depends on the graft's porosity [16] and it should be such that favors good healing and perfusion without being responsible for endoleaks or blood ultrafiltration.

Fabric erosion occurs because the endograft is a moving prosthesis composed of metal stents and soft fabric [17]. To prevent such a problem and consequent endoleaks, if new devices are composed by a stent and a graft, fabrics should be resistant to wear and tear, especially near the holes made by sewing the stent to the graft. Additionally, stents must exhibit excellent corrosion resistance and exhibit outstanding surface finish with very low roughness in order to prevent graft abrasion [18].

Radial force is another crucial feature in the design of a stent-graft. This force is important, not only for stents to stay open without being crushed with muscular activity, but also to provide a good seal and to ensure a secure fixation. When defining this parameter, it is necessary to make a trade-off: the device must be in its place without damaging the endothelium cells. In order to minimize stent-graft migration, currently, some devices have barbs; however, if the prosthesis fails, removing it is almost impossible due to the damages inflicted in the artery wall.

Radiopacity is an essential trait given that it is necessary to trace the stent-graft during the deployment and follow the evolution of the device within the patient's arteries.

Stent-grafts should have a low profile to facilitate the deployment and minimize lesions in the access arteries. From the selection point of view, a wide range of diameters and lengths is useful and, it is convenient if the materials used have a predictable behavior, that is, it is possible to foresee how much the device will dilate or shrink. 
Currently, after an EVAR, patients are regularly submitted to imaging exams to evaluate the size of the aneurysm sac and detect complications, such as endoleaks, endograft migration and module disconnection. The ideal stent-graft should be designed to avoid these expensive, and potentially harmful, exams; a possible solution is to include auto-diagnostic capabilities.

Regarding the device's manufacture, besides being cost-effective, the processes adopted should be environmentally acceptable, in addition to assuring a high and consistent quality.

Some of the features listed above are "yes" or "no" answers, that is, if a material does not meet that requirement it is automatically excluded. However, others features, like the radial force, are difficult to define because trade-offs have to be made. In these cases, by building a house of quality would it is possible to determine the relations between the multiple requirements and find the most suitable value.

\section{Current materials}

Since Parodi's stent-graft, these devices have not known significant changes regarding both the configuration and the materials used. Grafts are mainly made of expanded polytetrafluoroethylene (PTFE) or polyester (PET, Dacron). However, the graft of the Quantum Lp (Cordis Endovascular, Miami, USA) was an exception since it was made of polyurethane foam [19]. The most common material used in stents is Nitinol, a nickel titanium alloy. Nevertheless, some devices use 300 series stainless steel, and the Powerlink (Endologix, Irvine, USA) uses a cobalt chromium alloy (Elgiloy) instead [20]. The attachment of the stents to the grafts can be made either using thermal processes or sewing; when the latter technique is used, polyester or polypropylene sutures are employed. To enhance, and even ensure, radiopacity, some devices have radiopaque markers whose materials currently are platinum, platinum-iridium, tantalum and gold. 
The main characteristics of the materials used nowadays are pointed out bellow.

\section{Polyethylene terephthalate}

Polyethylene terephthalate, sometimes written polyethyleneterephthalate or poly(ethylene terephthalate), is a thermoplastic of the polyester family whose acronym is PET and, when made into fiber, is commercialized under the name Dacron.

PET is the largest volume synthetic fiber produced worldwide due to its low cost, convenient processability, and excellent and tailorable performance [21]. In terms of biomedical applications, this polymer is the most important of its family because of its chemical and physical properties, Table 2. For use in stent-grafts, its primary attributes are dimensional stability, durability, resistance to sterilization and biodegradation [22].

Dacron fabrics can be either knitted or woven. The latter technique involves at least two sets of yarns - one warp (longitudinal) and one filling (crosswise) - laced at right angles to each other, Fig. 3. The fabric's characteristics can be varied modifying parameters such as the type of weave, thread spacing, linear density and twist factors of the warp and filling yarns. In comparison with other structures, woven fabrics are dimensionally stable but less extensible and porous.

Woven fabrics can be manufactured in thin profiles, but they tend to wrinkle easily and have limited ability to conform to sinuous tubular shapes [23]. Nonetheless, crimping techniques can be used to increase flexibility, distensibility and kinkresistance [24].

Typically, grafts use one of two kinds of weaves: plain weave and twill weave. Plain weave fabrics are very resistant but have low flexibility due to each warp contacting with each weft reducing yarns mobility. In twill weaves, the weft - or filling yarn passes over one or more warp yarns and then under two or more warp yarns; this braid geometry produces reduced contact surface between yarns conferring good 
resistance and flexibility. Figures $3 b$ and $3 c$ show these types of weaves that were observed in graft materials.

Nowadays, several PET geometry yarns can be found in the market, ranging from monofilaments with rectangular cross-section $\left(16 \times 7 \mu \mathrm{m}^{2}\right.$ and larger yarn dimensions) to thin monofilaments (10-12.5 $\mu \mathrm{m}$ diameter) that result in thinner and flatter grafts with increased wear resistance (Fig. 4) [18].

As far as knitted fabrics are concerned, they are divided into two basic types: warpknit (similar to tricot) and weft-knit (like a hand-knit sweater), Fig. 5. While in the first technique the loops made from each warp are formed along the length of the fabric, in weft knitting the loops made by each weft thread are formed substantially across the width of the fabric.

Weft-knitted structures are highly extensible although the dimensional stability can be compromised if additional yarns are not used to interlock the loops and reduce the extension while increasing elastic recovery. Warp-knitted textiles are extremely versatile, and can be engineered with a variety of mechanical properties matching those of woven structures.

Like woven fabrics, the flexibility along with the pore size and distribution of knitted structures can be controlled, varying the density of the knit. Compared with woven grafts, knitted ones are more flexible and radially distensible. A potential limitation of knitted materials is the high porosity, which cannot be reduced below a certain value determined by the construction but can be overcome by preclotting the grafts with gelatin, collagen, and albumin [16]. However, published data shows that, after implantation, knitted grafts suffer a higher dilation [25].

ePTFE

Polytetrafluoroethylene (PTFE), Table 2, is a remarkably versatile polymer. It was patented in 1937 by DuPont as Teflon; however, it was in the late 1960s that Gore 
discovered that rapidly stretching PTFE under the right conditions created a strong and microporous material, the expanded PTFE (ePTFE).

As far as medical applications are concerned, the properties of ePTFE make it a standard material. This polymer is biocompatible and, due to its chemical structure, is highly nonreactive and nontoxic when implanted in biological tissues [26]. Its low coefficient of friction (the lowest of all materials) associated with its low surface tension are correlated to a high-velocity flow that resists bacterial growth[27] and favours a low thrombogenicity and modest tissue ingrowth [23]. ePTFE is chemically stable and, so far, no substance has been found to dissolve it. In addition, it is impermeable and has a diminished water adsorption capacity in spite of its porous structure. This last characteristic provides ePTFE a better modulus match than other polymers for many soft biological tissue applications [26].

Compared with polyester, PTFE's surface has less thrombogenesis than that of woven polyester. What could be pointed out as an advantage, in fact, is not, at least in the case of an aortic aneurysm because, in this situation, a material like Dacron would help coagulate the stagnant blood flow in the excluded aneurism sac. With regard to the tissue reaction, PTFE is preferable to polyester because, while PTFE causes a low-grade tissue reaction, the other more readily induces an inflammatory tissue reaction and granulation [28]. As far as dimensional stability is concerned, PTFE is preferable to Dacron since data indicates that the latter tends to dilate more than PTFE [29]. Despite the several advantages claimed by ePTFE, studies regarding abrasion resistance show a much lower resistance of these fabrics when compared with PET grafts [18].

ePTFE grafts are normally manufactured by an extrusion process. In this technique, PTFE is blended with a lubricant to form a paste. Before placing it in the extrusion equipment, the paste is crushed, using high pressure, to form a billet. The extruded PTFE is then cut into the desired lengths and placed in a low temperature oven to dry. Following, the material is stretched enabling the conversion of extruded PTFE 
to expanded PTFE, which results in a structure with controlled porosity, with a node-fibril microstructure in which solid nodes connect through fine fibrils (Fig. 6). The ePTFE is next placed into the sintering oven. After this point, secondary operations may be performed.

The majority of ePTFE used in medical applications has an intermodal distance of approximately $30 \mu \mathrm{m}$, because of the initial success of vascular grafts with this microstructure. However, the ability to tailor ePTFE implants during manufacturing has not been exploited, even though it is possible to manufacture ePTFE with internodal distances ranging from 1 to $100 \mu \mathrm{m}$ [26].

\section{Polyurethane}

Polyurethanes, also known as PUR or, more commonly, as PU, are copolymers that compose a family of polymers in which the chain of organic units is joined by urethane links.

Although PUs were originally developed in the 1930s as surface coatings, foams and adhesives [24], in the late 1950s, they started to be used in biomedical applications, e.g., as a foam breast prosthesis, and, in the 1960s, became a current material in catheters and pacemaker lead insulators. Concerning stent-grafts, nowadays, only the graft of the Quantum Lp (Cordis Endovascular, Miami, USA), which is in phase III of clinical trials for FDA approval, used this material in an open lattice matrix of polyurethane foam.

Polyurethanes are known for their good biocompatibility, high tensile strength, superior abrasion resistance and fatigue properties, as well as lubricity, ease of handling and processing versatility. Furthermore, for a given application, it is possible to adjust the polymer's properties, altering its chemical composition.

Current vascular PUs are elastomeric, which means that they have full elastic recovery within the stress limits imposed. In one hand, it is advantageous because 
after deployment, the device remains stressed but, on the other, the permanent elastic loading accelerates degradation [23].

\section{Nitinol}

Nitinol, an acronym for NiTi Naval Ordnance Laboratory, is an alloy composed of nickel ( $\mathrm{Ni}$ ) - between $49.5 \%$ and $57.5 \%$ - and balance titanium (Ti). In biomedical applications, the 55 -Nitinol ( 55 weight\% $\mathrm{Ni}$ ) is the most common due to its shape memory properties that allow the creation of complex shapes and its ductility at low temperatures [31].

Superelasticity and the shape memory effect are two of the most prominent features of these alloys. Both characteristics derive from a solid-state transformation, from martensitic to austenitic, which can be triggered thermally or mechanically, and are dependent on the composition and processing history of the material [32].

Superelastic Nitinol exhibits a hysteretic stress-strain relationship similar to the behavior of natural materials. This feature, which usually is regarded as a drawback in traditional engineering applications, is useful in the design of stent-grafts because it is responsible for a constant force against the organ wall and resistance to crushing. Along with the shape memory effect, superelasticity is important during the device's deployment to help the stent-graft acquire its final shape. In addition, both properties are crucial to resist kinking or, more suitably, recover from crushing [33].

Regarding Nitinol's fatigue resistance, literature indicates lower endurance values when compared with those of others metals used as stent structures (e.g., stainless steel and Elgiloy). However, this subject is still under research with limited information available. While the quasi-static tension and compression properties of Nitinol are reasonably well characterized, its fatigue behavior is not. Nitinol strength is widely influenced by the mechanical cycling and by the effect of cycling 
temperature [34]. Furthermore, the non-linear nature of the superelastic phase transformation in Nitinol means that conventional fatigue life theory is difficult to apply. The volume fraction of martensitic/austenitic phases and its role in the fatigue mechanism is still not clearly understood [35]. Many additional factors can affect the fatigue behavior of Nitinol alloys, like microstructure, surface quality, type of loading, degree of order of the lattices and particles size distributions [36].

Nickel is known to be allergenic and toxic; however, Nitinol is biocompatible and, to improve its biocompatibility and corrosion resistance; studies are being carried out to eliminate $\mathrm{Ni}$ from the surface [37].

Nitinol is self-passivating, that is, it forms a stable oxide surface layer that protects the base material from general corrosion. Literature shows that the titanium-oxide layer formed remains essentially unchanged after implantation but samples from surrounding tissues from the vascular wall around Nitinol stents has revealed tiny deposits of nickel and titanium compounds, which means that corrosion products have been formed and certainly have diffused through the passive layer, thus reaching surrounding tissues [38]. To prevent this from happening, passivation treatments, such as electropolishing or chemical passivation, are needed. These techniques contribute to the elimination of many surface irregularities that are the starting point for stress fractures or erosive pits and increase the stability of the surface by protecting the bulk material from corrosion, thus increasing the device's durability [39].

\section{Stainless steel}

$316 \mathrm{~L}$ stainless steels, commonly used as stents, are austenitic iron-based alloys that contain a minimum of $10.5 \% \mathrm{Cr}$ (chromium), the amount necessary to form a passive oxide, and 8 to $15 \%$ Nickel to stabilize austenite at room temperature. They have excellent formability, which is controlled by the Ni content, and the low 
carbon content associated with additions of molybdenum, and niobium makes it resistant to corrosion, Table 4.

Like Nitinol, this steel can release some of its compounds into tissues and fluids. To prevent this from happening, surface modifications are needed. Among the treatments available, the ion implantation technique is one of the commonly used to improve wear and corrosion resistance of stents. For example, is proved that $\mathrm{N}+$ ion implantation with 1016 ions $/ \mathrm{cm}^{2}$ improve the corrosion resistance of stainless steel [40]. Another treatment currently used in surface modifications is electropolishing, where the wire surface is oxidized by a single of a mixed acidic electrolyte [41].

\section{Elgiloy}

Elgiloy is a cobalt-nickel-chromium-iron alloy with typical compositions, in wt \% (weight percent), of $39.0 \pm 41.0 \mathrm{Co}$ (cobalt), $19.0 \pm 21.0 \mathrm{Cr}, 14.0 \pm 16.0 \mathrm{Ni}, 6.0 \pm 8.0$ Mo (molybdenum), 1.5 $\pm 2.5 \mathrm{Mn}$ (manganese), 0.10 max. Be (beryllium), 0.15 max. C (carbon), and balance of Fe (iron) [42]. It is a high-performance engineering material characterized by high strength and ductility as well as good mechanical properties, corrosion resistance and excellent fatigue life. As it is biocompatible, it is applied in medical applications as surgical implants and instruments, Table 4.

Elgiloy presents strength and elongation as high as those of stainless steel [43] and has superior wear resistance [44].

The chromium oxide layer formed by this alloy confers a resistance to corrosion. In in vitro studies, nitinol and cobalt alloys may be considered more resistant to corrosion than $316 \mathrm{~L}$ stainless steel when passivated according to ASTM F86 [45].

In spite of having good mechanical properties, only two stent grafts made with Elgiloy are currently in the market: Powerlink and Lifepath. However, Lifepath is only used in Europe. In EUA, clinical trials have been halted due to wireform fractures detected and to allow modifications in the device [19]. 
Furthermore, and in spite of its strong paramagnetism, some authors identified relatively large artifacts when magnetic resonance imaging (MRI) was performed $[42,46]$. This happens because the clusters of magnetic elements, which prevail in Co- $\mathrm{Cr}$ alloys, cause heterogeneity on the atomic scale of the material [42].

\section{Materials: Future trends}

Typically, materials for biomedical applications are biocompatible and sterilizable and have appropriate mechanical and physical properties. During the selection process, the designer seeks materials with good processability for ease of manufacturing and tends to neglect cost [47]. However, the increase of human life expectancy and the rise of medical expenses will probably change this. The cost will then become another variable that will narrow the limited list of materials suitable to be used inside the human body.

\section{Materials for stents}

Stent-grafts can be either balloon-expandable or self-expanding. While the formers are manufactured in the deliverable configuration, and balloon-dilated to the final diameter inside the vessel, self-expanding stent-grafts are manufactured in the expanded shape, compressed and constrained in a delivery system, and, upon release, spring back to the preset diameter.

The materials used for balloon-expandable devices (notice that these devices are rare) are plastically deformed through the inflation of a balloon and, after the balloon is deflated, suffer a slight recoil caused by the elastic portion of the deformation. Therefore, the ideal material for these devices should have low yield stress, to make it deformable at manageable balloon pressures, and high elastic modulus for minimal recoil. In addition to the mechanical behavior, they should have enhanced radiopacity, good corrosion resistance and good MRI compatibility. Possible materials for these types of stents are tantalum, platinum alloys, niobium alloys and cobalt alloys [48-50]. 
During the design of stent-grafts, attention must be given to galvanic corrosion. Thus, the use of multiple alloys should be avoided.

\section{Ultra high molecular weight polyethylene}

Ultra high molecular weight polyethylene (UHMWPE or UHMW), a subset of the thermoplastic polyethylene, is also known as high-modulus polyethylene (HMPE) or high-performance polyethylene (HPPE). Its polymerization began in the 1950 s and one decade later it became the material of choice for total joint arthroplasty in orthopedic and spine implants due to its excellent biocompatibility, high impact strength and remarkable wear resistance [51], Table 6. During the 1970s, the Dutch chemical company DSM started the commercialization of UHMWPE fibers that are nowadays widely used in ballistic protection, defense applications, and in medical devices.

Compared with polyester, UHMWPE fibers elicit fewer inflammatory and irritating responses while promoting equal or better healing. Furthermore, they offer exceptional fatigue resistance and strength allowing the design of lesser invasive devices with the same or even higher strength.

Besides being self-lubricant, UHMWPE has an extremely low coefficient of friction and a non-stick surface, which results in very smooth and slippery devices. As the fibers are durable, stable, flexible and resistant to abrasion, they represent a good choice for moving prosthesis such as stent-grafts. Furthermore, this nonporous material has a good chemical resistance and negligible water absorption.

It is important to notice that all virgin UHMWPE grades are in compliance with US Food and Drug Administration regulations and have received US Department of Agriculture approval. However, further studies regarding the application of this material in grafts are required. 


\section{Conclusions}

Currently, an ideal stent-graft can be described as being biocompatible, non-toxic and non-carcinogenic. It has a stable configuration, and it is flexible, conformable and durable. Regarding the mechanical properties, it is resistant to wear, fatigue and corrosion. It is ductile and tough and has an optimal porosity. The ideal device must also be versatile to successfully address as many anatomies as possible.

A stent-graft is expected to be compatible with standard angiographic techniques to permit its precise deployment and follow-up within the patient's arteries. Nonetheless, the ideal device, should also provide information regarding the device's performance to the doctors.

Commercial stent-grafts are made of two components: a graft, typically made of ePTFE or Dacron, and a stent, made of either stainless steel or Nitinol. To improve the endoprosthesis performance, new materials and designs are already being pursued but there are other materials, such as UHMWPE, that have reveled potential to improve the current generation of commercial stent-grafts.

\section{Acknowledgments}

The authors want to thank to Dr. Roncon de Albuquerque and Dr. Sérgio Sampaio from Hospital São João, Porto, Portugal, and to Dr. Duarte Medeiros from Hospital Egas Moniz, Lisboa, Portugal for their support.

The first author wishes to thank Fundação para a Ciência e Tecnologia (FCT), in Portugal, for the financial support provided by the PhD grant with reference SFRH/BD/42967/2008.

The work was partially supported by the project "SenseCardioHealth: New technological solutions for smart cardiovascular medical devices" - MIT-Pt/EDAMEMD/0007/2008, sponsored by FEDER through COMPETE and Portuguese funds through FCT. 
The authors wish to thank Miguel Marafuz (http://illustrationmfz.wordpress.com/)

for the illustrations.

The authors want to thank to Cook Europe for the materials support.

\section{References}

1 Johnston, K.W., Robert, B.R., Tilson, M.D., Dhiraj, M.S., Larry, H. and James, C.S. Suggested standards for reporting on arterial aneurysms. Journal of Vascular Surgery, 1991, 13(3), 452-458.

2 Ramanath, V.S., Oh, J.K., Sundt, T.M. and Eagle, K.a. Acute aortic syndromes and thoracic aortic aneurysm. Mayo Clinic proceedings. Mayo Clinic, 2009, 84(5), 465-481.

3 Ricotta II, J.J., Malgor, R.D. and Oderich, G.S. Endovascular Abdominal Aortic Aneurysm Repair: Part I. Annals of Vascular Surgery, 2009, 23(6), 799-812.

4 Kouchoukos, N.T. and Dougenis, D. Surgery of the thoracic aorta. The New England journal of medicine, 1997, 336(26), 1876-1876.

5 Myers, K., Devine, T., Barras, C. and Self, G. Endoluminal versus Open repair for Abdominal Aortic Aneurysms 2nd Virtual Congress of Cardiology Argentine, 2001).

6 Norwood, M.G.A., Lloyd, G.M., Bown, M.J., Fishwick, G., London, N.J . and Sayers, R.D. Endovascular abdominal aortic aneurysm repair. Postgraduate Medical J ournal, 2007, 83(975), 21-27.

7 Blankensteijn, J.D., Lindenburg, F.P., Van Der Graaf, Y. and Eikelboom, B.C. Influence of study design on reported mortality and morbidity rates after abdominal aortic aneurysm repair. British Journal of Surgery, 1998, 85(12), 1624-1630.

8 Greenhalgh, R.M. Comparison of endovascular aneurysm repair with open repair in patients with abdominal aortic aneurysm (EVAR trial 1), 30day operative mortality results: randomised controlled trial. The Lancet, 2004, 364(9437), 843-848.

9 Dake, M.D., Miller, D.C., Semba, C.P., Mitchell, R.S. and Walker, P.J. Transluminal placement of endovascular stent-grafts for the treatment of descending thoracic aortic aneurysms. New England Journal of Medicine, 1994, 331(26), 1729-1734.

10 Coggia, M., Javerliat, I ., Di Centa, I ., Colacchio, G., Cerceau, P., Kitzis, M. and Goëau-Brissonnière, O.A. Total laparoscopic infrarenal aortic aneurysm repair: Preliminary results. Journal of Vascular Surgery, 2004, 40(3), 448-454.

11 Fukui, S., Gigou, F., Daneshvar, M., Marteau, V., Soury, P., Petit, M.-D. and Laurian, C. Totally laparoscopic assisted thoracic aorta endograft delivery by direct sheath placement into the aorta. Journal of vascular surgery : official publication, the Society for Vascular Surgery [and] International Society for Cardiovascular Surgery, North American Chapter, 2006, 43(6), 1274-1277.

12 Cao, P., Verzini, F., Rango, P.D., Maritati, G., Pasquale, F.D. and Parlani, G. Different types of thoracic endografts. Journal of Cardiovascular Surgery, 2009, 50(4), 483-492. 
13 Monahan, T.S. and Schneider, D.B. Fenestrated and Branched Stent Grafts for Repair of Complex Aortic Aneurysms. Seminars in Vascular Surgery, 2009, 22(3), 132-139.

14 Soor, G.S., Chakrabarti, M.O., Abraham, J.R., Leong, S.W., Vukin, I., Lindsay, T. and Butany, J. Aortic stent grafts. Journal of Clinical Pathology, 2008, 61(7), 794-801.

15 Machado, L.G. and Savi, M.A. Medical applications of shape memory alloys. Brazilian Journal of Medical and Biological Research, 2003, 36, 683-691.

16 Rutherford, R.B. Vascular surgery. (Saunders, 2005).

17 Katzen, B.T. and MacLean, A.A. Complications of endovascular repair of abdominal aortic aneurysms: A review. CardioVascular and Interventional Radiology, 2006, 29(6), 935-946.

18 Rodrigues, A., Figueiredo, L. and Bordado, J. Abrasion behavior of polymeric textiles for endovascular stent-grafts ICOBT 2011 International Conference on BioTribology London, 2011).

19 Criado, F.J., Barnatan, M.F., Lingelbach, J.M., Mills, J.D., Richards, B.E. and Morgan, W.R. Abdominal aortic aneurysm: Overview of stent-graft devices. Journal of the American College of Surgeons, 2002, 194(1, Supplement 1), S88-S97.

20 van der Laan, M.J., Bartels, L.W., Bakker, C.J.G., Viergever, M.A. and Blankensteijn, J.D. Suitability of 7 aortic stent-graft models for MRI-based surveillance. Journal of Endovascular Therapy, 2004, 11(4), 366-371.

21 Handbook of fiber chemestry. (CRC Press, 2007).

22 Wong, J.Y. and Bronzino, J.D. Biomaterials. (CRC Press, 2007).

23 Palmaz, J.C. Review of polymeric graft materials for endovascular applications. Journal of Vascular and Interventional Radiology, 1998, 9(1), 7-13.

24 Xue, L. and Greisler, H.P. Biomaterials in the development and future of vascular grafts. Journal of Vascular Surgery, 2003, 37(2), 472480.

25 Alimi, Y., J uhan, C., Morati, N., Girard, N. and Cohen, S. Dilation of woven and knitted aortic prosthetic grafts: CT scan evaluation. Annals of Vascular Surgery, 1994, 8(3), 238-242.

26 Catanese, J., Cooke, D., Maas, C. and Pruitt, L. Mechanical properties of medical grade expanded polytetrafluoroethylene: The effects of internodal distance, density, and displacement rate. Journal of Biomedical Materials Research, 1999, 48(2), 187-192.

27 I nternational, A. Engineering plastics. (ASM International, 1988).

28 Suzuki, K., I shiguchi, T., Kawatsu, S., I wai, H., Maruyama, K. and Ishigaki, T. Dilatation of stent-grafts by luminal pressures: Experimental evaluation of polytetrafluoroethylene (PTFE) and woven polyester grafts CardioVascular and Interventional Radiology, 2001, 24(2), 94-98.

29 Schroeder, T.V., Eldrup, N., Just, S., Hansen, M., Nyhuus, B. and Sillesen, H. Dilatation of aortic grafts over time: What to expect and when to be concerned. Seminars in Vascular Surgery, 2009, 22(2), 119124.

30 Limited, G.D. CES Edupack 2010. 2010).

31 The Biomedical Engineering Handbook. (CRC Press, 1999). 
32 Stoeckel, D., Pelton, A. and Duerig, T. Self-expanding nitinol stents: material and design considerations European Radiology, 2004, 14(2), 292-301.

33 Stoeckel, D. Nitinol medical devices and implants. Minimally Invasive Therapy and Allied Technologies, 2000, 9(2), 81-88.

34 De la Flor, S., Urbina, C. and Ferrando, F. Effect of mechanical cycling on stabilizing the transformation behaviour of NiTi shape memory alloys. Journal of Alloys and Compounds, 2009, 469(1-2), 343-349.

35 Medical Device Materials: Proceedings from the Materials \& Processes for Medical Devices Conference 2003, 8-10 September 2003, Anaheim, CA, Editor: Shrivastava, S., ASM International, 2003.

36 Eggeler, G., Hornbogen, E., Yawny, A., Heckmann, A. and Wagner, $\mathbf{M}$. Structural and functional fatigue of NiTi shape memory alloys. Materials Science and Engineering: A, 2004, 378(1-2), 24-33.

37 Shabalovskaya, S., Anderegg, J. and Van Humbeeck, J. Critical overview of Nitinol surfaces and their modifications for medical applications. Acta Biomaterialia, 2008, 4(3), 447-467.

38 Lévesque, J., Dubé, D., Fiset, M. and Mantovani, D. Materials and properties for coronary stents. Advanced Materials \& Processes, 2004(September), 45-48.

39 Duerig, T., Pelton, A. and Stöckel, D. An overview of nitinol medical applications. Materials Science and Engineering: A, 1999, 273275(0), 149-160.

40 Kathuria, Y.P. The potential of biocompatible metallic stents and preventing restenosis. Materials Science and Engineering: A, 2006, 417(12), 40-48.

41 Shih, C.-C., Shih, C.-M., Su, Y.-Y., Su, L.H.J., Chang, M.-S. and Lin, S.-J. Effect of surface oxide properties on corrosion resistance of 316L stainless steel for biomedical applications. Corrosion Science, 2004, 46(2), 427-441.

42 Ho, J.C. and Shellock, F.G. Magnetic properties of Ni-Co-Cr-base Elgiloy. Journal of Materials Science: Materials in Medicine, 1999, 10(9), 555-560.

43 Hanawa, T. Materials for metallic stents. Journal of Artificial Organs, 2009, 12(2), 73-79.

44 Niinomi, M. Recent metallic materials for biomedical applications. Metallurgical and Materials Transactions A, 2002, 33(3), 477-486.

45 Thierry, B. and Tabrizian, M. Biocompatibility and Biostability of Metallic Endovascular Implants: State of the Art and Perspectives. Journal of Endovascular Therapy, 2003, 10(4), 807-824.

46 van Dijk, L.C., van Holten, J., van Dijk, B.P., Matheijssen, N.A.A. and Pattynama, P.M.T. A Precious Metal Alloy for Construction of MR Imaging-compatible Balloon-expandable Vascular Stents1. Radiology, 2001, 219(1), 284-287.

47 Puskas, J.E. and Chen, Y. Biomedical application of commercial polymers and novel polyisobutylene-based thermoplastic elastomers for soft tissue replacement. Biomacromolecules, 2004, 5(4), 1141-1154.

48 O'Brien, B., Stinson, J. and Carroll, W. Development of a new niobium-based alloy for vascular stent applications. Journal of the Mechanical Behavior of Biomedical Materials, 2008, 1(4), 303-312.

49 Mani, G., Feldman, M.D., Patel, D. and Agrawal, C.M. Coronary stents: A materials perspective. Biomaterials, 2007, 28(9), 1689-1710. 
50 O'Brien, B.J., Stinson, J.S., Larsen, S.R., Eppihimer, M.J. and Carroll, W.M. A platinum-chromium steel for cardiovascular stents. Biomaterials, 2010, 31(14), 3755-3761.

51 Park, K., Lewis, G. and Park, J.B. Ultra-High Molecular Weight Polyethylene (UHMWPE). Encyclopedia of Biomaterials and Biomedical Engineering, 2004, 1690 - 1696.

52 Ryhänen, J. Biocompatibility evaluation of nickel-titanium shape memory metal alloy. Departments of Surgery, Anatomy and Pathology (University of Oulu, Oulu University Library, 1999).

53 Ryhänen, J. Biocompatibility evaluation of nickel-titanium shape memory metal alloy. (Oulu University Library, 2000).

54 Saigal, A. and Fonte, M. Solid, shape recovered "Bulk" nitinol: Part II-Mechanical properties. Materials Science and Engineering: A, 2011, 528(16-17), 5551-5559.

55 Nayan, N., Buravalla, V. and Ramamurty, U. Effect of mechanical cycling on the stress-strain response of a martensitic Nitinol shape memory alloy. Materials Science and Engineering A, 2009(525), 60-67. 


\section{FI GURE CAPTI ONS}

Fig. 1: Representation of a normal aorta, (A) a thoracic aortic aneurysm located behind the heart, and (B) an abdominal aortic aneurysm located below the renal arteries.

Fig. 2: Possible end configurations of stent-grafts, from left to right and from top to bottom: (a) scalloped flares, (b) straight cut, (c) bare stent with an extra spring, (d) straight open, (e) double stent, (f) bare stent and ( $g$ ) bare stent with protection.

Fig. 3: Woven fabric: (a) schematic representation; the vertical thread is the "warp yarn" direction while the horizontal represents the "weft yarn" or "filling", (b) SEM of an endovascular prosthesis woven fabric with plain weave pattern, (c) SEM of an endovascular prosthesis woven fabric with twill weave pattern.

Fig. 4: SEM of endovascular prosthesis fabric, showing the braid and the geometry of the fibers: (a) PET-LP (PET low profile), (b) PET.

Fig. 5: Knitted fabrics: (a) warp-knit, (b) weft-knit.

Fig. 6: SEM of ePTFE showing the polymeric node-fibril microstructure. 


\section{TABLE CAPTI ONS}

Table 1: Stent-graft classification.

Table 2: PET, PTFE and PU foam physical properties (adapted from [30]).

Table 3: Stainless steel and Elgiloy physical properties (adapted from [30] and [52]).

Table 4: UHMWPE physical properties (adapted from [30]). 
FI GURES

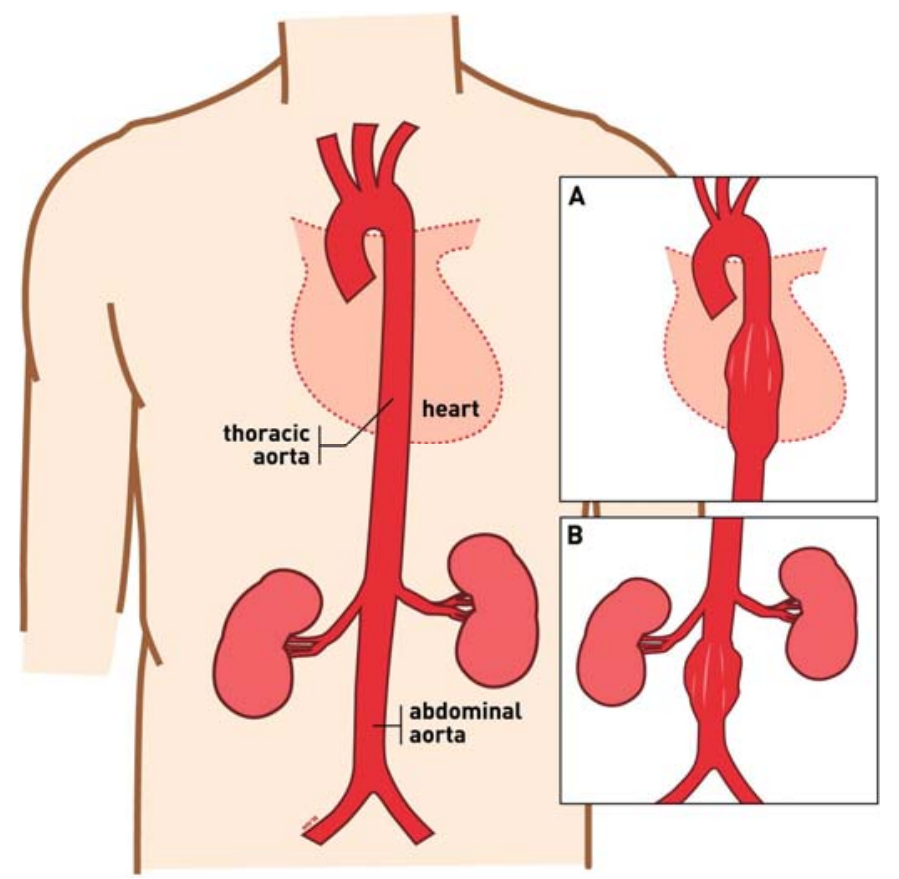

Figure 1
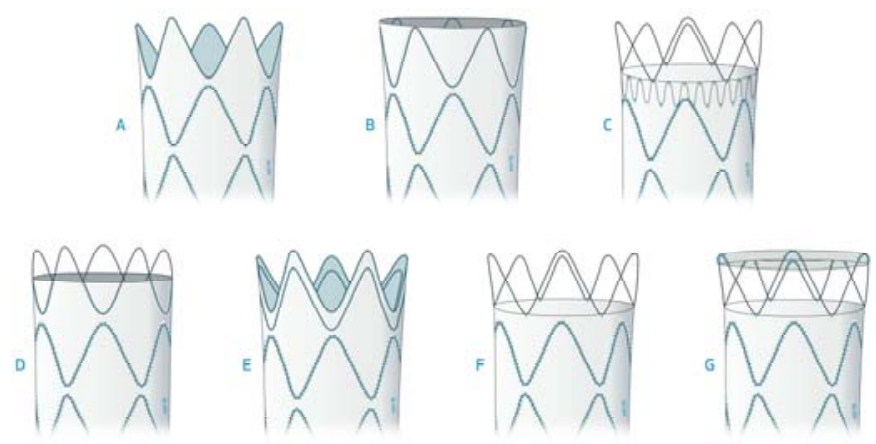

Figure 2 


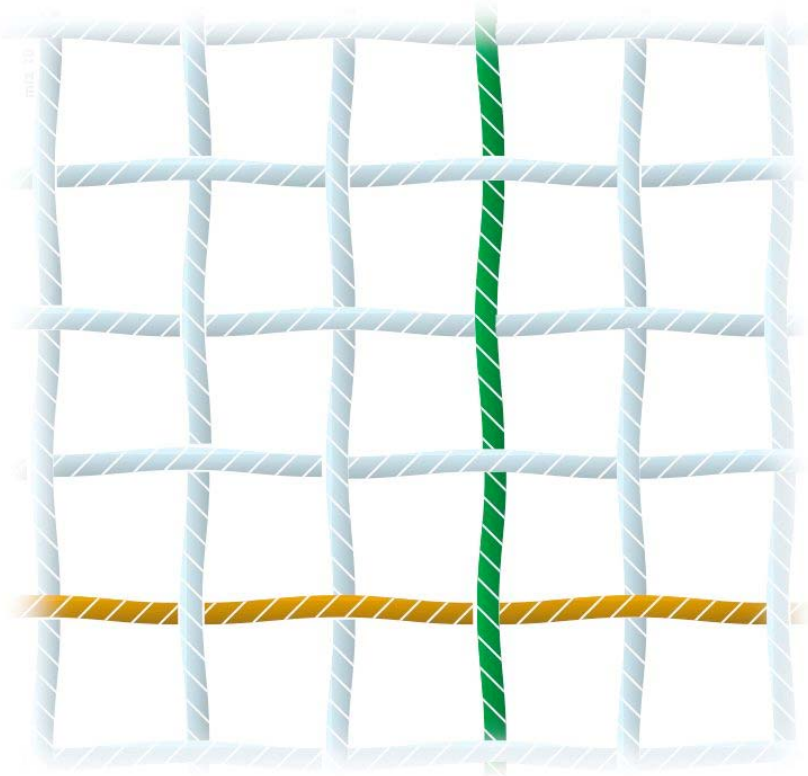

Figure $3 a$

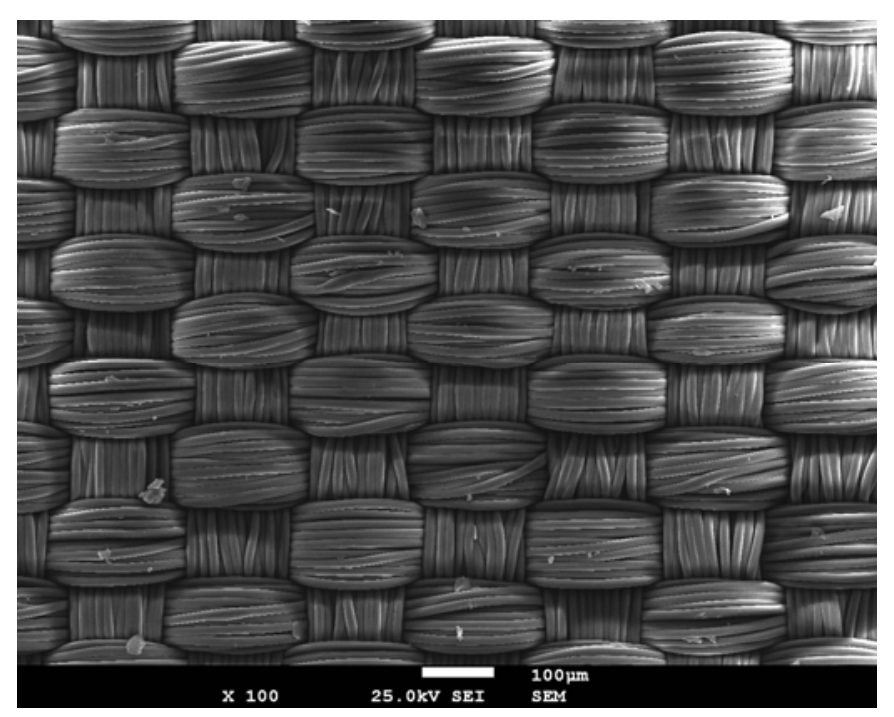

Figure $3 b$ 


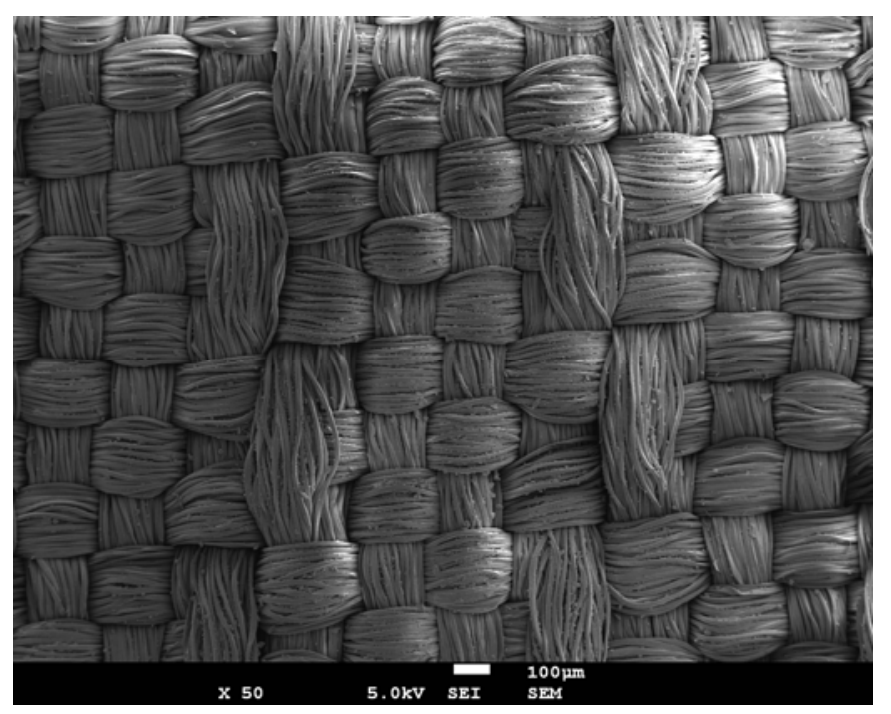

Figure 3c

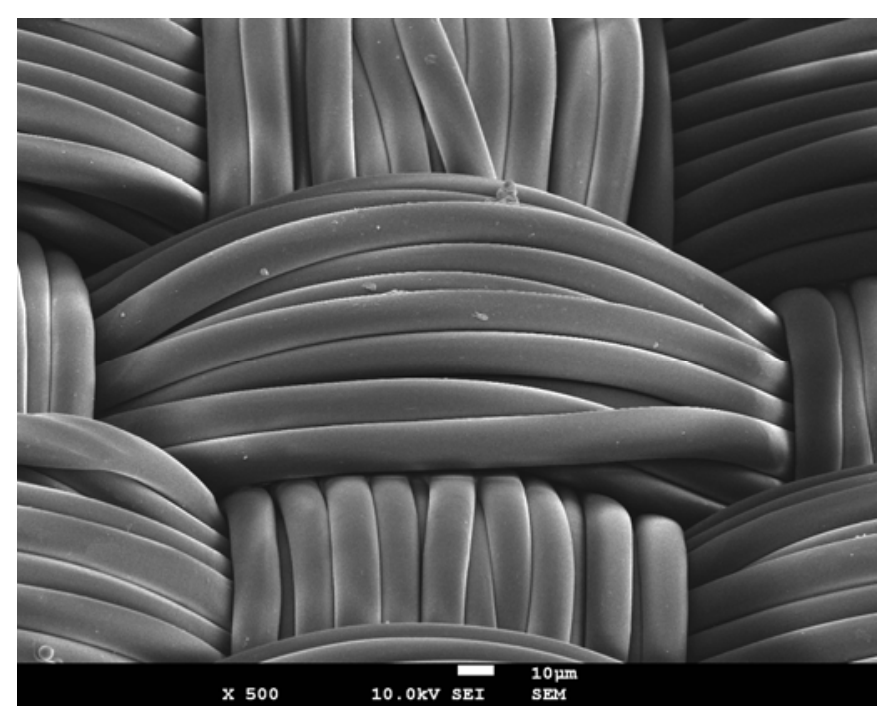

Figure 4a 


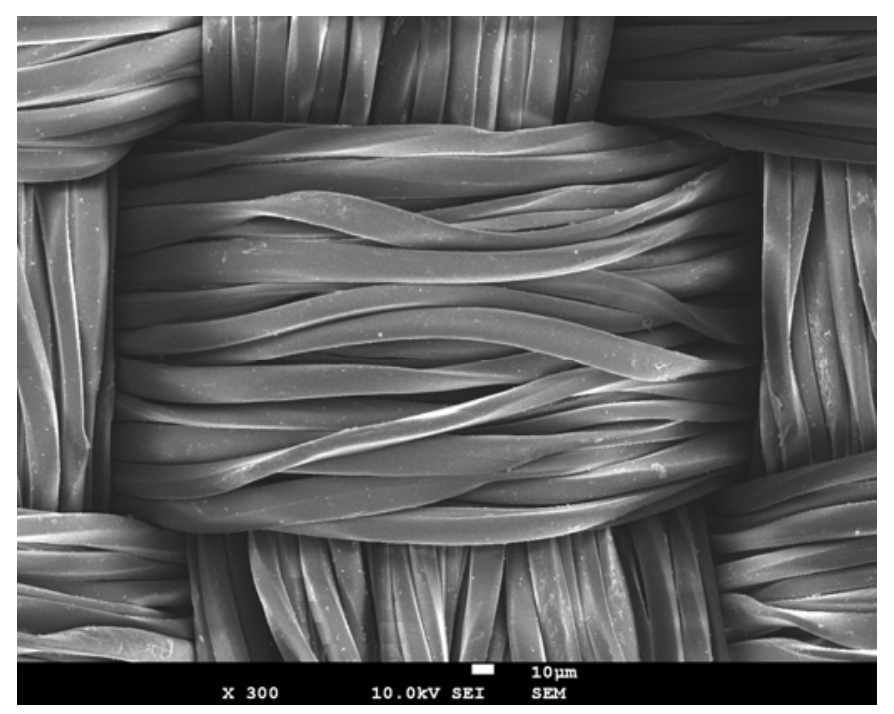

Figure $4 b$

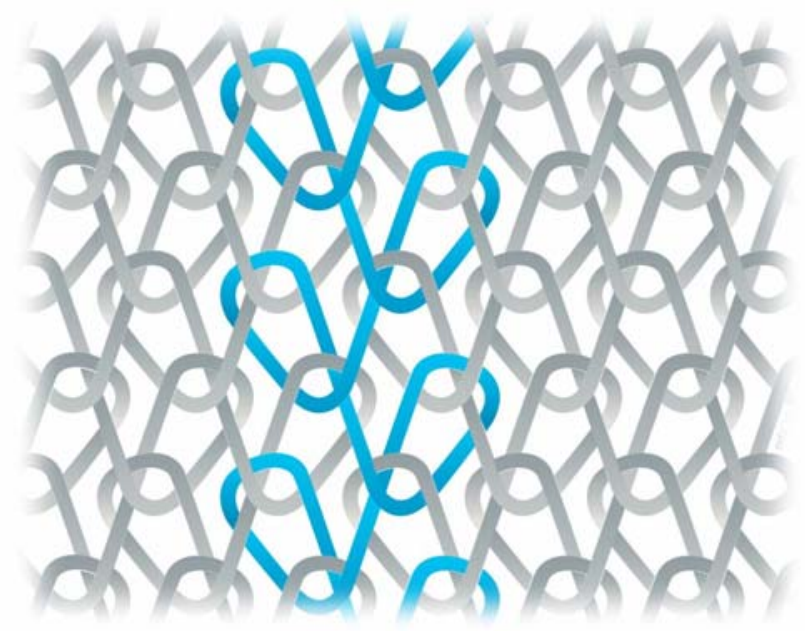

Figure 5a 


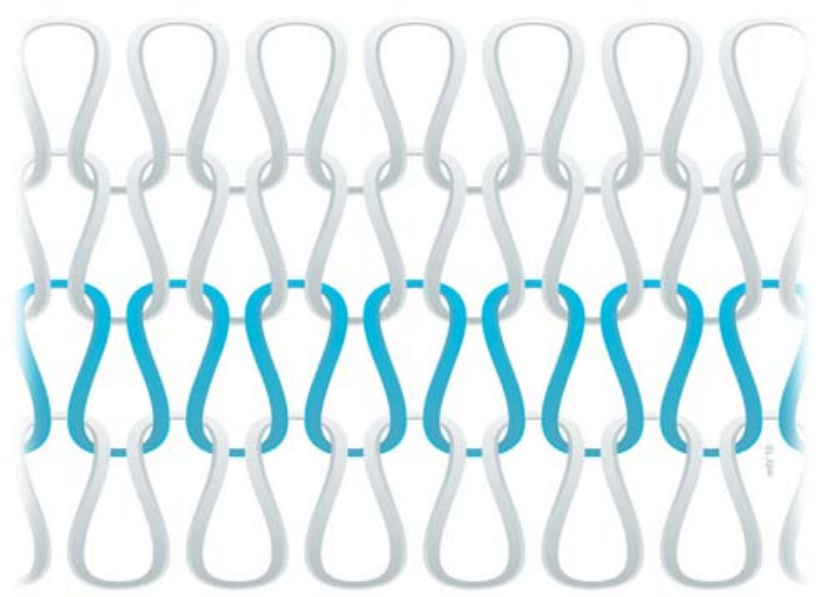

Figure 5b

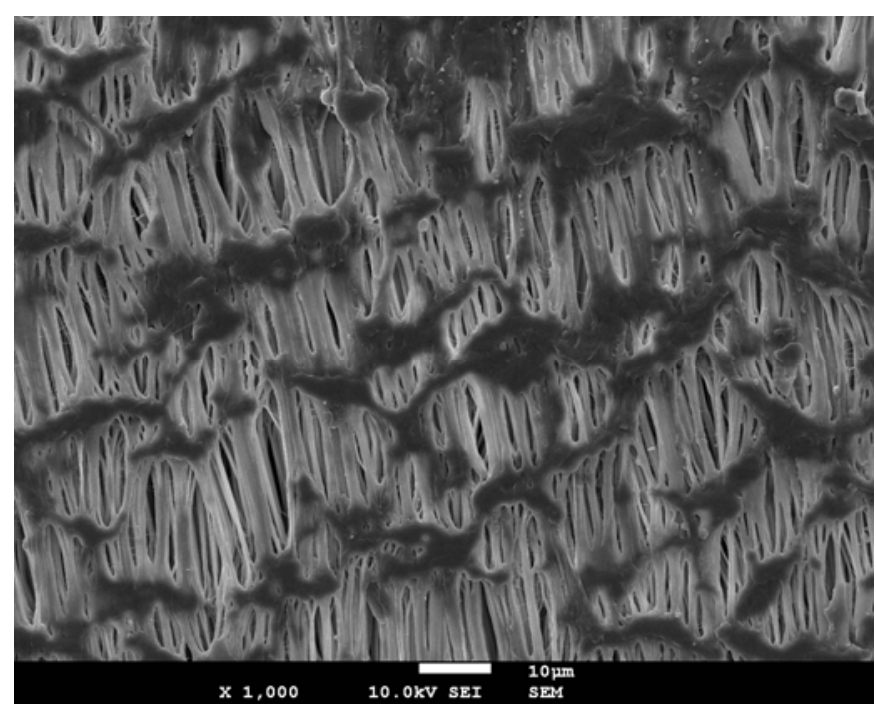

Figure 6 
TABLES

TABLE 1

\begin{tabular}{|c|c|}
\hline Location & $\begin{array}{l}\text { Thoracic } \\
\text { Abdominal } \\
\text { Peripheral }\end{array}$ \\
\hline Shape & $\begin{array}{l}\text { Tubular } \\
\text { Bifurcated } \\
\text { Fenestrated (only custom-made) }\end{array}$ \\
\hline Diameter & $\begin{array}{l}\text { Tapered } \\
\text { Flared } \\
\text { Non tapered }\end{array}$ \\
\hline Deployment technique & $\begin{array}{l}\text { Self-expanding } \\
\text { Balloon inflated }\end{array}$ \\
\hline Release mode & $\begin{array}{l}\text { Expansion from end to end } \\
\text { Expansion from middle to end }\end{array}$ \\
\hline Fixation & $\begin{array}{l}\text { Radial force (without hook or barbs) } \\
\text { With hooks or barbs }\end{array}$ \\
\hline Pattern of the stent & $\begin{array}{l}\text { Sinusoidal (wave shape) } \\
\text { M-shaped } \\
\text { Diamond } \\
\text { Multiple rings } \\
\text { Spiral winding (no commercial device available) }\end{array}$ \\
\hline Methods of graft manufacturing & $\begin{array}{l}\text { Knitted } \\
\text { Woven } \\
\text { Extruded }\end{array}$ \\
\hline
\end{tabular}




\begin{tabular}{|c|c|c|c|}
\hline Property & $\begin{array}{c}\text { PET } \\
\text { amorphous }\end{array}$ & $\begin{array}{c}\text { PTFE } \\
\text { semi-crystalline }\end{array}$ & $\begin{array}{c}\text { PU foam } \\
0.022 \text { specific gravity }\end{array}$ \\
\hline Diameter $(\mu \mathrm{m})$ & $10-50$ & $20.7-24.3$ & -- \\
\hline Moment of inertia (m4) & $\begin{array}{c}4.91 \times 10-22 \\
- \\
3.07 \times 10-19\end{array}$ & $\begin{array}{c}9.01 \times 10-21 \\
- \\
1.71 \times 10-20\end{array}$ & -- \\
\hline Density $\left(\mathrm{Kg} / \mathrm{m}^{3}\right)$ & $1290-1390$ & $2140-2200$ & $2000-2400$ \\
\hline Glass transition temperature $\left({ }^{\circ} \mathrm{C}\right)$ & 107 to 125 & 67.9 to 79.9 & -- \\
\hline Young's modulus (Gpa) & $2.8-3$ & $0.4-0.552$ & $7.2 e-5-8 e-5$ \\
\hline Compressive modulus (Gpa) & $2.76-4.14$ & $0.402-0.423$ & -- \\
\hline Flexural modulus (Gpa) & $2.41-3.09$ & $0.537-0.564$ & $7.2 e-5-8 e-5$ \\
\hline Yield strength (Gpa) & $50-55$ & $19.7-21.7$ & $0.003-0.0035$ \\
\hline Tensile strength (Gpa) & $55-60$ & $20.7-34.5$ & $0.12-0.13$ \\
\hline Elongation (\% strain) & $280-320$ & $200-400$ & $170-180$ \\
\hline Fatigue strength at $10^{\wedge} 7$ cycles (Mpa) a & $19.3-29$ & $5.75-7$ & $0.084-0.091$ \\
\hline Tenacity (N/tex) & $0.1-0.5$ & $1-2$ & -- \\
\hline Breaking tenacity ( $\mathrm{g} /$ denier) & 9.2 & 1.7 & -- \\
\hline Friction coefficient & $0.39-0.44$ & $0.01-0.05$ & -- \\
\hline Abrasion resistance & Very Good & Fair & -- \\
\hline Water absorption at $24 \mathrm{hrs}(\%) \mathrm{b}$ & $0.14-0.18$ & $0.005-0.01$ & $8-10$ \\
\hline Permeability $\mathrm{O} 2\left(\left(\mathrm{~cm}^{3} \cdot \mathrm{mm}\right) /\left(\mathrm{m}^{2}\right.\right.$.day.atm $\left.)\right) \mathrm{c}$ & $1.2-2.77$ & $218-363$ & -- \\
\hline Biocompatibility & Good & Excellent & -- \\
\hline Price $(€ / \mathrm{kg})$ & $1.24-1.36$ & $8.17-15.5$ & $7.69-12.3$ \\
\hline \multicolumn{4}{|c|}{$\begin{array}{l}\text { a Maximum cyclic stress for which the material survives } 10^{7} \text { cycles. } \\
\text { b Weight gain (\%) after a sample of test material is immersed in distilled water at room temperature for } \\
24 \mathrm{hrs} \text {. }\end{array}$} \\
\hline
\end{tabular}


${ }^{c}$ Oxygen permeability is the volume of oxygen that will pass through a unit thickness of material per unit area per unit time per unit barometric pressure $\left(\left(\mathrm{cm}^{3} \cdot \mathrm{mm}\right) /\left(\mathrm{m}^{2} \cdot\right.\right.$ day. $\left.\left.\mathrm{atm}\right)\right)$. 
TABLE 3

\begin{tabular}{|c|c|c|c|c|}
\hline \multirow[t]{2}{*}{ Property } & \multirow[t]{2}{*}{$\begin{array}{l}\text { Stainless steel } \\
316 \mathrm{~L} \text { wrought }\end{array}$} & \multirow[t]{2}{*}{$\begin{array}{l}\text { Elgiloy } \\
\text { annealed }\end{array}$} & \multicolumn{2}{|c|}{$\begin{array}{l}\text { Nitinol [53] } \\
\mathrm{Ni}_{55} \mathrm{Ti}_{45}\end{array}$} \\
\hline & & & Austenitic & Martensitic \\
\hline Density $\left(\mathrm{Kg} / \mathrm{m}^{3}\right)$ & $7870-8070$ & 8300 & \multicolumn{2}{|c|}{6450} \\
\hline Young's modulus (GPa) & $190-205$ & $198-211$ & $70-110$ & $21-69$ \\
\hline Yield strength (GPa) & $170-310$ & $446-455$ & $100-800$ & $50-300$ \\
\hline Tensile strength (GPa) & $480-620$ & $808-942$ & $800-1500$ & $103-1100$ \\
\hline Elongation (\% strain) & $30-50$ & $64.4-65.7$ & $1-20$ & up to 60 \\
\hline Fatigue strength at $10^{7}$ cycles (MPa) & $256-307$ & $428-432$ & $\begin{array}{l}124-190 \\
{[54,55]}\end{array}$ & $\begin{array}{c}130-150 \\
{[55]}\end{array}$ \\
\hline Corrosion resistance & Good & Fair & \multicolumn{2}{|c|}{ Good to Excellent } \\
\hline Biocompatibility & Good & Fair & \multicolumn{2}{|c|}{ Good } \\
\hline Price $(€ / \mathrm{kg})$ & $3.9-4.3$ & $14.9-16.4$ & \multicolumn{2}{|c|}{$>100$} \\
\hline
\end{tabular}


TABLE 5

\begin{tabular}{|l|c|}
\hline \multicolumn{1}{|c|}{ Property } & UHMWPE \\
\hline Diameter $(\mu \mathrm{m})$ & $12-21$ \\
\hline Moment of inertia (m4) & $1.02 \times 10-21$ \\
& $9.55 \times 10-21$ \\
\hline Density (Kg/m $\left.{ }^{3}\right)$ & $931-949$ \\
\hline Glass transition temperature ( $\left.{ }^{\circ} \mathrm{C}\right)$ & -130 to -91.2 \\
\hline Young's modulus (GPa) & $0.894-0.963$ \\
\hline Compressive modulus (GPa) & $0.894-0.963$ \\
\hline Flexural modulus (GPa) & $0.894-0.963$ \\
\hline Yield strength (GPa) & $21.4-27.6$ \\
\hline Tensile strength (GPa) & $38.6-48.3$ \\
\hline Elongation (\% strain) & $350-525$ \\
\hline Fatigue strength at 10^7 cycles (MPa) & $15.2-19.8$ \\
\hline Tenacity (N/tex) & $26-34$ \\
\hline Breaking tenacity (g/denier) & $0.005-0.01$ \\
\hline Friction coefficient & Excellent \\
\hline Abrasion resistance & \\
\hline Water absorption at 24 hrs (\%) & \\
\hline Biocompatibility & \\
\hline Price ( $€ /$ Kg) & \\
\hline
\end{tabular}

